九州大学学術情報リポジトリ

Kyushu University Institutional Repository

\title{
China's Agricultural Trade Cost Elasticity: Estimates from Using Translog Gravity Model
}

\section{MENG, Dan}

College of Economics and Management, Nanjing Agricultural University | Laboratory of Quantitative Food Economic Analysis, Division of Agricultural and Resource Economics, Department of Agricultural and Resource Economics, Faculty of Agriculture, Kyushu University

\section{MAEDA, Koshi}

\section{WANG, Xue jun}

Tariff changes go along with other types of reforms that might also affect trade. Moreover, tariffs might be driven by trade

https://doi.org/10.5109/1911233

出版情報：九州大学大学院農学研究院紀要. 63 (1)，pp.177-184，2018-02-27. Faculty of Agriculture, Kyushu University

バージョン :

権利関係 : 


\title{
China's Agricultural Trade Cost Elasticity: Estimates from Using Translog Gravity Model
}

\author{
Dan MENG ${ }^{1}$, Koshi MAEDA and Xuejun WANG ${ }^{1 *}$ \\ Laboratory of Quantitative Food Economic Analysis, Division of Agricultural and \\ Resource Economics, Department of Agricultural and Resource Economics, \\ Faculty of Agriculture, Kyushu University, Fukuoka 812-8581, Japan \\ (Received October 31, 2017 and accepted November 20, 2017)
}

\begin{abstract}
The elasticity of trade flows with respect to trade costs involve important implications that quantify welfare gains from trade and predict the effects of trade policy on trade flows. The major purposes of this study are to estimate China's agricultural trade-cost elasticity and to analyze its heterogeneity across different types of trading partners. A micro-founded method based on the translog gravity model developed by Novy (2013) is applied to measure the trade-cost elasticity of China's agricultural products using a panel dataset of its major trading partners. First, the estimation results show that there was an obviously negative relationship between the import share of trading partners with respect to China's agricultural products and its corresponding trade-cost elasticity. Specifically, the higher the import share of trading partners with respect to China's agricultural products, the lower the weighted average trade-cost elasticity. Second, the weighted average trade-cost elasticity of aggregate agriculture experienced a rapid downward trend from 1996 to 2016. The trade-cost elasticity fell from 13.68 in 1996 to 6.54 in 2016. Finally, the trade-cost elasticity measure presents significant heterogeneity across various types of trading partners.
\end{abstract}

Key words: Agricultural products, China, Trade-cost elasticity, Translog gravity

\section{INTRODUCTION}

In recent years, China has pursued export-oriented economic policies and experienced a sharp increase in trade with the rest of the world. China's integration into the global economy is largely due to its participation in bilateral and multilateral trade agreements. A large empirical body of literature has shown that China's average trade costs have experienced substantial declines since its trade policy reforms (Shi, 2008; Fang et al., 2010; Xu and Liang, 2010). However, this evidence applies to the aggregated level rather than to the industry specific level, such as the agricultural sector, where special and differential treatments are accepted by multilateral and bilateral trade agreements. Wang et al. (2016) demonstrated that China's agricultural exports experienced a modest downward trend in trade costs from 1995-2011. China's agricultural trade costs continue to exist and are much larger than those in non-agricultural sectors. This observation raises a question. By how much do trade costs impede China's agricultural exports? The trade cost elasticity regarding the link between trade costs and trade flows is a crucial parameter to answer this question. Meanwhile, obtaining a correct measure for the trade cost elasticity is also useful in the prediction of the effects of trade policies on trade flows and welfare. Unfortunately, we have little direct information on China's agricultural trade cost elasticity.

There is considerable interest in the literature for the estimation of trade cost elasticity. Romalis (2007) and Caliendo and Parro (2012) identify trade elasticity from variations in tariffs. Eaton and Kortum (2002) and

\footnotetext{
1 College of Economics and Management, Nanjing Agricultural University, Nanjing 210095, China

* Corresponding author (E-mail: wangxj@njau.edu.cn)
}

Simonovska and Waugh (2012) employ price differences across countries as a proxy for trade costs to obtain an estimate of trade elasticity. The estimators that employ tariff data suffer from endogeneity and omitted variable bias $^{1}$. The approaches used by Eaton and Kortum (2002) and Simonovska and Waugh (2012) are restricted to trade in goods where tariffs and price data are available. Novy (2013) developed a translog gravity model to measure the elasticity of trade flows with respect to trade costs. Due to more flexible substitution patterns across goods, translog gravity breaks the constant trade cost elasticity that is the hallmark of traditional gravity equations. Contrary to the standard gravity equation that implies constant trade cost elasticity, the translog gravity equation generates endogenous trade cost elasticity. Another advantage is that the translog gravity model is parsimonious in its data requirements and relatively simple to empirically implement.

Therefore, this paper uses the translog gravity approach to measure the elasticity of China's agricultural trade flows with respect to trade costs. The rest of the paper is organized as follows. Section 2 briefly explains the estimation approach of trade cost elasticity developed by Novy (2013). Section 3 introduces our data and their sources. In Section 4, we use the translog gravity model to measure the elasticity of China's agricultural trade flows with respect to trade costs. In the last section, we discuss our findings and conclude the paper.

\section{TRANSLOG GRAVITY MODEL}

The gravity model, a work-horse of international trade analysis, has been used to refer to a variety of dif-

${ }^{1}$ Tariff changes go along with other types of reforms that might also affect trade. Moreover, tariffs might be driven by trade. 
ferent specifications of the determinants of bilateral trade. However, leading trade models from the current literature imply a gravity equation that is characterized by a constant elasticity of trade flows with respect to trade costs. This means that, for a given change in trade costs, trade is expected to react by the same percentage for all bilateral trading pairs. Novy (2013) challenges this "one size fits all" feature and derives a gravity equation from homothetic translog preferences in a general equilibrium framework. Translog preferences are more flexible since they allow for richer substitution patterns across the different varieties of exports. This flexibility allows the translog gravity equation to estimate the heterogeneous impacts of trade costs across pairs. Based on Novy (2013), we use the translog gravity model to measure the elasticity of China's agricultural trade flows with respect to trade costs. In addition to its key feature of endogenous trade-cost elasticity, the translog gravity model is appealing because it is parsimonious in its data requirements and relatively simple to empirically implement.

Novy (2013) derives the following gravity equation for import shares $\left(\frac{x_{i j}}{y_{j}}\right)$ based on a translog demand system.

$$
\begin{aligned}
\frac{x_{i j}}{y_{j}} & =\frac{y_{j}}{y^{W}}-\gamma n_{i} \ln \left(t_{i j}\right)+\gamma n_{i} \ln \left(T_{j}\right) \\
& +\gamma n_{i} \sum_{s=1}^{J} \frac{y_{s}}{y^{W}} \ln \left(\frac{t_{i s}}{T_{S}}\right),
\end{aligned}
$$

where $x_{i j}$ denotes the value of exports from exporting country $i$ to importing country $j$, and $y_{j}$ denotes the income of country $j . y^{W}$ is world income, defined as $y^{W}$ $\equiv \sum_{j=1}^{J} y_{j} \cdot n_{i}$ is the number of goods for country $i \cdot \gamma$ denotes translog parameter.

$t_{i j}$ is the bilateral trade costs, which is given as a loglinear function of observable trade cost proxies:

$$
\ln \left(t_{i j}\right)=\rho \ln \left(d i s t_{i j}\right)+\delta a d j_{i j},
$$

2 The trade cost elasticity equation can be obtained as follow

$$
\eta_{i j}=\frac{d \ln \left(x_{i j} / y_{j}\right)}{d \ln \left(t_{i j}\right)}=\frac{1}{\left(x_{i j} / y_{j}\right)} \cdot \frac{d\left(x_{i j} / y_{j}\right)}{d \ln \left(t_{i j}\right)}
$$

Due to the term $\frac{d \ln \left(x_{i j} / y_{j}\right)}{d \ln \left(t_{i j}\right)}$ corresponds to the distance coefficient in equation $(1),-\gamma n_{i}$, we have

$$
\eta_{i j}=\frac{-\gamma n_{i}}{\left(x_{i j} / y_{j}\right)}
$$

Given the standard gravity equation as Anderson and Wincoop (2003) $x_{i j}=\frac{y_{i} y_{j}}{y^{W}}\left(\frac{t_{i j}}{\Pi P}\right)^{1-\sigma}$ where $t_{i j}$ is the bilateral trade cost measure, $\Pi_{i}$ is the outward multilateral resistance of country $i$, and $P_{j}$ is the inward multilateral resistance of country $j$. $\sigma>1$ is the elasticity of substitution across goods.

Divide each side of the above equation by $y_{j}$, and then take logarithms of both side, we have

$$
\ln \left(\frac{x_{i j}}{y_{j}}\right)=\ln \left(\frac{y_{j}}{y^{W}}\right)-(\sigma-1) \ln \left(t_{i j}\right)+(\sigma-1) \ln \left(\Pi_{i}\right)+(\sigma-1) \ln \left(P_{j}\right) .
$$

Use the exporter fixed effect and the importer fixed effect to control for each country's multilateral trade resistance terms, we have

$$
\ln \left(\frac{x_{i j}}{y_{j}}\right)=-(\sigma-1) \rho \ln \left(d i s t_{i j}\right)-(\sigma-1) \delta a d j_{i j}+\tilde{S}_{i}+\tilde{S}_{j}+\varepsilon_{i j} .
$$
countries $i$ and $j$, which can be a proxy variable of $t_{i j}$. Another proxy variable is the adjacency dummy variable $a d j_{i j}$ that takes on the value 1 if country $i$ and country $j$ are a common border or 0 if they do not. $\rho$ is the discoefficient.

$\ln \left(T_{j}\right)$ is a weighted average of logarithmic trade costs over the trading partners of country $j$, akin to the inward multilateral resistance in Anderson and van

$$
\ln \left(T_{j}\right)=\frac{1}{N} \sum_{k=1}^{N} \ln \left(t_{k j}\right)=\sum_{s=1}^{J} \frac{n_{s}}{N} \ln \left(t_{s j}\right) .
$$

We substitute equation (2) into equation (3) to get

$$
\ln \left(T_{j}\right)=\rho \ln \left(T_{j}^{d i s t}\right)+\delta T_{j}^{a d j},
$$

where $\ln \left(T_{j}^{d i s t}\right) \equiv \sum_{s=1}^{J} \frac{n_{s}}{N} \ln \left(d i s t_{s j}\right)$ and $T_{j}^{a d j} \equiv \sum_{s=1}^{J} \frac{n_{s}}{N} a d j_{s j}$.

Since the first and last terms on the right-hand side of equation (1) do not vary over the importing country $j$, they can be captured by an exporter's fixed effect $S_{i}$ $\equiv \frac{y_{i}}{y^{W}}+r n_{i} \sum_{s=1}^{J} \frac{y_{s}}{y^{W}} \ln \left(\frac{t_{i s}}{T_{S}}\right)$. Then, by rewriting equation (1), we have

$$
\begin{aligned}
\frac{x_{i j}}{y_{j}}= & -\gamma \rho n_{i} \ln \left(d i s t_{i j}\right)+\gamma \rho n_{i} \ln \left(T_{j}^{d i s t}\right)-\gamma \delta n_{i} a d j_{i j} \\
& +\gamma \delta n_{i} T_{j}^{a d j}+S_{i}+\varepsilon_{i j},
\end{aligned}
$$

where $\varepsilon_{i j}$ is the mean-zero error term.

The trade cost elasticity follows from equation (1)

$$
\eta_{i j}=\frac{-\gamma n_{i}}{\left(x_{i j} / y_{j}\right)}
$$

The form of $\eta_{i j}$ allows trade costs to have a heterogeneous impact across country pairs. Specifically, ceteris paribus, the more that the destination country imports from a particular exporting country, the less sensitive its bilateral imports are to trade costs. where dist $_{i j}$ denotes the distance between the capitals of 
To calculate $\eta_{i j}$, the value of $\gamma$ is obtained as follows. First, we estimate the traditional gravity equation ${ }^{3}$

$$
\begin{aligned}
\ln \left(\frac{x_{i j}}{y_{j}}\right)= & -(\sigma-1) \rho \ln \left(\text { dist }_{i j}\right)-(\sigma-1) \delta a d j_{i j}+\widetilde{S}_{i}+ \\
& \widetilde{S}_{j}+\varepsilon_{i j},
\end{aligned}
$$

where the distance coefficient in equation (7) corresponds to the parameter combination $-(\sigma-1) \rho$. Under the assumption of an elasticity of substitution equal to $\sigma=8$, the value of $\rho$ can be obtained.

Then, we estimate equation (5) to obtain the distance coefficient $\gamma \rho$. Therefore, we can obtain the value of $\gamma$ using the above two steps.

\section{DATA}

Equation (6) is applied to calculate the trade-cost elasticity of China's agricultural exports to its 33 trading partners ${ }^{4}$ over a longer period (1996-2016). The major trading partners included in our analysis account for 80.25 percent of China's total agricultural exports during the sample period. We adopt HS classification and define agricultural products as all products from chapters (01) to (24) and from chapters (50) to (53) in the HS classification standards. The necessary data is primarily the exported agricultural trade data for China, sourced from the UN COMTRADE database and denominated in US dollars. We compiled a total of 684 observations over the years 1996-20165. The income data of trading partners are taken from the World Bank Development Indicators Annual Database (WDI), which is denominated in US dollars.

To obtain the value of $\gamma$, we need to regress the traditional gravity equation (7) and the translog estimating equation (5). In this analysis, the bilateral distance between capital cities and adjacency information between two countries were taken from the CEPII Database.

Before the regression, we need to calculate the multilateral resistance terms $\left(\ln \left(T_{j}^{d i s t}\right) \equiv \sum_{s=1}^{J} \frac{n_{s}}{N} \ln \left(\right.\right.$ dist $\left._{s j}\right)$ and $T_{j}^{a d j} \equiv \sum_{s=1}^{J} \frac{n_{s}}{N} a d j_{s j}$ ). To conduct this calculation, we required data on $n_{\mathrm{s}(s \pm C H N)}$, which is the number of goods that originate from country s. $n_{s}$ is not directly available, but by following the approach of Hummels and Klenow (2005), it can be expressed as the extensive margin of country $s$ relative to the rest of the world. The extensive margin is measured by weighting categories of goods by their overall importance in exports. We directly obtain the value of $n_{s}$ from Hummels and Klenow (2005). The value of $N$ is the sum of the extensive margin of 124 exporting countries ${ }^{6}$.

Regression results on the panel data are presented in Table 1. The regression coefficients of the explanatory variables are similar to the theoretical expectations. Combined with the traditional gravity equation, the coefficient on the variable $\ln \left(\right.$ dist $\left._{i j}\right)$ corresponds to $-(\sigma-1) \rho$. We can obtain $-(\sigma-1) \rho=-1.120$ from columns 1 and 2 . The elasticity of substitution is equal to $\sigma=8$, and we obtain the value of $\rho$ as 0.160 . As the translog estimating equation (5) shows, the coefficient on the variable $\ln \left(\right.$ dist $\left._{i j}\right)$ corresponds to $-\gamma \rho n_{i}$. We take -0.001 from columns 3 and 4 of Table 1 , since $\gamma \rho n_{i}=0.001$. We have already obtained $n_{i}=n_{C H N}=0.704$. Then, we get $\rho n_{i}=$ 0.113 . Then, the value of the translog parameter follows as $\gamma=0.009$. The trade-cost elasticity can be calculated across different import shares of trading partners with respect to China's agricultural products.

Table 1. Regression of translog estimating equation and traditional gravity estimating equation

\begin{tabular}{cll}
\hline & $\ln \left(\frac{x_{i j}}{y_{j}}\right)$ & \multicolumn{1}{c}{$\frac{x_{i j}}{y_{j}}$} \\
\hline $\ln \left(\right.$ dist $\left._{i j}\right)$ & $-1.120^{* * *}$ & $-0.001^{* *}$ \\
& $(-25.350)$ & $(-3.100)$ \\
$a d j_{i j}$ & $0.786^{* * *}$ & 0.000 \\
$\ln \left(T_{j}^{\text {dist }}\right)$ & $(6.330)$ & $(0.110)$ \\
& & 0.000 \\
$T_{j}^{a d j}$ & & $(0.210)$ \\
- & & - \\
${ }^{c o n s}$ & $1.493^{* * *}$ & 0.008 \\
$R^{2}$ & $(4.060)$ & $(1.000)$ \\
\hline
\end{tabular}

Notes: t-statistics (in parentheses) computed with White's heteroscedasticity-consistent standard errors. *, ** and *** indicates significance at the 10,5 and 1 percent levels, respectively.

\section{MEASUREMENT RESULTS}

We estimate bilateral trade-cost elasticity for China's agricultural products with its 33 trading partners over the sample period 1996-2016 (see Table 2). The main

${ }^{4}$ The 33 trading partners include China, Hong Kong(HKG),Japan(JPN), United States of America(USA), Republic of Korea(KOR),Thailand(THA), Malaysia(MYS), Bangladesh(BGD), Philippines(PHL), Indonesia(IDN), Russian Federation(RUS), Germany(DEU), Netherlands(NLD), Italy(ITA), United Kingdom(GBR), Canada(CAN), India(IND), Australia(AUS), Singapore(SGP), Spain(ESP), Mexico(MEX), Pakistan(PAK), Brazil(BRA), Benin(BEN), Nigeria(NGA), France(FRA), Myanmar(MMR), Togo(TGO), Belgium(BEL), Sri Lanka(LKA), Turkey(TUR), Egypt(EGY),Iran(IRN), South Africa(ZAF).

${ }_{5}^{5}$ The maximum number of observations is $33 * 21=693$, but 9 observations are missing.

${ }^{6}$ Hummels and Klenow (2005) measured the extensive margin of 126 exporting countries/regions, but in this paper we drop Congon and Taiwan.

${ }^{7}$ Measurement results show that the span of trade-cost elasticity is very large, which minimum value is 0.04 and maximum value is 1608. 
Table 2. Index of agricultural bilateral trade-cost elasticity between China and major trading partners

\begin{tabular}{|c|c|c|c|c|c|c|c|c|c|c|c|c|c|c|c|c|}
\hline & AUS & BEL & BEN & BGD & BRA & CAN & DEU & EGY & ESP & FRA & GBR & HKG & IDN & IND & IRN & ITA \\
\hline 1996 & 37.180 & - & 1.046 & 3.080 & 131.162 & 48.122 & 46.688 & 17.110 & 78.149 & 85.826 & 52.406 & 0.290 & 12.207 & 32.831 & 1607.041 & 41.654 \\
\hline 1997 & 36.028 & - & 0.853 & 2.699 & 128.588 & 52.936 & 41.648 & 22.838 & 49.520 & 83.504 & 66.102 & 0.294 & 7.481 & 35.943 & 309.816 & 33.159 \\
\hline 1998 & 32.320 & - & 0.518 & 2.615 & 149.967 & 48.100 & 34.276 & 18.910 & 38.170 & 79.478 & 69.531 & 0.342 & 1.832 & 25.126 & 33.816 & 37.843 \\
\hline 1999 & 25.125 & 25.061 & 0.450 & 2.118 & 130.813 & 51.528 & 40.028 & 8.711 & 38.511 & 98.977 & 64.857 & 0.376 & 2.832 & 13.723 & 92.467 & 30.113 \\
\hline 2000 & 30.119 & 21.813 & 0.421 & 1.790 & 220.731 & 40.809 & 32.792 & 12.172 & 30.309 & 82.859 & 59.427 & 0.378 & 3.084 & 16.880 & 57.434 & 20.780 \\
\hline 2001 & 25.349 & 24.335 & 0.276 & 1.957 & 169.834 & 35.749 & 30.139 & 12.180 & 31.619 & 77.805 & 54.313 & 0.377 & 3.900 & 17.364 & 189.980 & 22.840 \\
\hline 2002 & 22.307 & 32.006 & 1.437 & 2.466 & 104.978 & 33.722 & 33.925 & 16.181 & 59.688 & 109.783 & 60.698 & 0.350 & 2.994 & 16.425 & 66.775 & 26.099 \\
\hline 2003 & 18.725 & 20.075 & 0.237 & 1.335 & 121.749 & 31.603 & 32.380 & 8.653 & 56.466 & 105.469 & 53.686 & 0.261 & 3.126 & 14.336 & 7.057 & 25.836 \\
\hline 2004 & 20.281 & & & 1.256 & & & & 4.001 & & & & & & & & 26.242 \\
\hline 2005 & 21.477 & 11.047 & 0.134 & 0.998 & 77.757 & 25.442 & 24.273 & 7.505 & 24.844 & 83.472 & 48.925 & 0.263 & 3.843 & 10.751 & 12.075 & 19.883 \\
\hline 2006 & 17.565 & 10.486 & 0.103 & 0.809 & 61.679 & 24.558 & 20.989 & 6.954 & 22.698 & 65.097 & 42.250 & 0.263 & 3.398 & 11.968 & 43.616 & 17.440 \\
\hline 2007 & 15.777 & 10.478 & 0.079 & 0.794 & 76.547 & 22.040 & 19.708 & 7.593 & 21.487 & 61.891 & 42.939 & 0.276 & 2.904 & 13.682 & 35.443 & 17.407 \\
\hline 2008 & 15.498 & 9.381 & 0.061 & 0.725 & 31.646 & 20.195 & 18.522 & 5.724 & 22.254 & 51.603 & 33.891 & 0.277 & 3.538 & 13.851 & 46.228 & 16.278 \\
\hline 2009 & 14.131 & 10.061 & 0.074 & 0.803 & 49.334 & 18.042 & 19.067 & 6.743 & 22.140 & 54.923 & 30.055 & 0.293 & 3.327 & 13.599 & 33.477 & 19.002 \\
\hline 2010 & 14.488 & 8.022 & 0.070 & 0.622 & 24.838 & 17.412 & 15.836 & 6.937 & 15.535 & 49.361 & 24.606 & 0.259 & 2.825 & 13.779 & 26.291 & 13.004 \\
\hline 2011 & 13.403 & 7.830 & 0.077 & 0.531 & 22.928 & 16.925 & 14.554 & 5.209 & 13.259 & 42.113 & 22.098 & 0.251 & 2.775 & 15.488 & 25.706 & 11.020 \\
\hline 2012 & 14.909 & 7.532 & 0.113 & 0.545 & 24.535 & 15.552 & 14.544 & 5.971 & 15.127 & 42.468 & 23.283 & 0.245 & 3.232 & 15.277 & 30.720 & 13.736 \\
\hline 2013 & 13.758 & 7.835 & 0.082 & 0.526 & 20.850 & 16.516 & 14.988 & 6.328 & 13.676 & 42.408 & 21.134 & 0.216 & 3.379 & 14.452 & 31.571 & 12.618 \\
\hline 2014 & 12.571 & 8.390 & 0.089 & 0.599 & 26.407 & 15.377 & 14.786 & 6.585 & 13.470 & 43.211 & 23.149 & 0.224 & 3.082 & 16.956 & 17.422 & 13.035 \\
\hline 2015 & 12.370 & 7.698 & 0.103 & 0.640 & 23.623 & 13.808 & - & 6.368 & 11.940 & 38.469 & 22.947 & 0.243 & 3.308 & 18.883 & 9.132 & 12.394 \\
\hline 2016 & 10.909 & 8.159 & 0.160 & 0.704 & 22.443 & 12.493 & 15.397 & 7.471 & 11.207 & 39.546 & 21.362 & 0.240 & 3.236 & 20.295 & - & 12.756 \\
\hline
\end{tabular}

Table 2. Continued

\begin{tabular}{|c|c|c|c|c|c|c|c|c|c|c|c|c|c|c|c|c|c|}
\hline & JPN & KOR & LKA & MEX & MMR & MYS & NGA & NLD & PAK & PHL & RUS & SGP & TGO & THA & TUR & USA & $\mathrm{ZAF}$ \\
\hline 1996 & 7.886 & 4.186 & 5.282 & 627.550 & - & 4.554 & 55.127 & 9.480 & 11.857 & 2.250 & 7.305 & 1.305 & 0.481 & 15.785 & 75.443 & 80.679 & 28.976 \\
\hline 1997 & 7.584 & 3.066 & 3.636 & 330.222 & - & 2.084 & 42.037 & 10.652 & 8.762 & 2.420 & 9.123 & 1.731 & 0.623 & 11.726 & 36.005 & 77.040 & 26.128 \\
\hline 1998 & 7.623 & 3.167 & 3.303 & 170.573 & - & 2.124 & 47.899 & 12.092 & 27.627 & 1.393 & 7.108 & 2.692 & 0.956 & 12.131 & 99.132 & 81.520 & 23.221 \\
\hline 1999 & 7.964 & 2.995 & 2.805 & 162.529 & - & 1.938 & 26.148 & 12.531 & 20.204 & 3.321 & 9.224 & 3.082 & 0.970 & 8.064 & 82.783 & 80.042 & 23.219 \\
\hline 2000 & 7.460 & 2.391 & 2.406 & 112.003 & 1.359 & 1.775 & 14.568 & 9.809 & 8.724 & 3.205 & 12.578 & 3.421 & 0.701 & 5.361 & 46.544 & 68.687 & 20.105 \\
\hline 2001 & 6.279 & 2.305 & 1.828 & 91.459 & 0.662 & 2.111 & 12.272 & 9.902 & 18.921 & 3.461 & 10.525 & 3.066 & 0.428 & 6.658 & 41.536 & 69.880 & 18.692 \\
\hline 2002 & 6.109 & 2.295 & 2.369 & 67.216 & 0.602 & 1.524 & 35.051 & 13.973 & 10.257 & 2.966 & 6.684 & 2.922 & 1.804 & 6.101 & 45.716 & 57.990 & 11.856 \\
\hline 2003 & 6.097 & 2.009 & 1.396 & 31.220 & 0.879 & 1.404 & 7.365 & 14.195 & 11.943 & 2.057 & 6.423 & 2.577 & 0.344 & 4.394 & 22.675 & 46.392 & 9.425 \\
\hline 2004 & 5.429 & 2.557 & 1.383 & 18.573 & 0.886 & 1.913 & 12.665 & 14.298 & 10.266 & 2.147 & 8.482 & 2.714 & 0.169 & 4.241 & 24.497 & 44.013 & 16.212 \\
\hline 2005 & 5.037 & 2.299 & 1.457 & 24.063 & 1.071 & 1.713 & 14.623 & 11.320 & 4.278 & 2.150 & 9.181 & 2.766 & 0.147 & 3.929 & 17.742 & 37.703 & 15.929 \\
\hline 2006 & 4.612 & 2.476 & 1.524 & 20.809 & 0.959 & 1.646 & 17.744 & 8.547 & 5.505 & 1.908 & 9.082 & 3.040 & 0.117 & 3.713 & 18.464 & 30.360 & 12.375 \\
\hline 2007 & 4.573 & 2.310 & 1.386 & 22.909 & 1.258 & 1.547 & 18.805 & 7.690 & 5.993 & 1.996 & 9.070 & 3.803 & 0.100 & 3.352 & 16.888 & 27.399 & 11.260 \\
\hline 2008 & 5.544 & 2.345 & 1.610 & 19.443 & 2.074 & 1.589 & 9.881 & 8.485 & 6.466 & 2.332 & 10.282 & 3.229 & 0.093 & 2.726 & 18.762 & 24.328 & 10.198 \\
\hline 2009 & 5.853 & 2.322 & 1.846 & 16.573 & 2.230 & 1.276 & 6.480 & 8.287 & 4.370 & 1.745 & 9.216 & 3.160 & 0.088 & 2.384 & 19.149 & 26.157 & 9.341 \\
\hline 2010 & 5.328 & 2.183 & 1.814 & 14.802 & 2.263 & 1.227 & 12.537 & 6.756 & 3.244 & 1.869 & 8.629 & 3.427 & 0.059 & 2.039 & 11.544 & 21.879 & 10.587 \\
\hline 2011 & 4.746 & 2.065 & 1.679 & 11.537 & 2.073 & 1.144 & 7.869 & 6.199 & 3.467 & 1.616 & 8.891 & 3.512 & 0.047 & 1.633 & 10.876 & 19.611 & 9.442 \\
\hline 2012 & 4.435 & 2.238 & 1.720 & 13.326 & 1.688 & 1.146 & 7.467 & 6.023 & 3.482 & 1.318 & 9.407 & 3.522 & 0.042 & 1.505 & 15.009 & 19.206 & 8.588 \\
\hline 2013 & 3.942 & 2.261 & 1.679 & 13.156 & 1.243 & 0.981 & 8.042 & 5.943 & 3.855 & 1.092 & 8.990 & 2.946 & 0.057 & 1.317 & 13.850 & 19.552 & 8.495 \\
\hline 2014 & 3.759 & 2.239 & 1.633 & 13.017 & 0.974 & 0.987 & 9.356 & 5.642 & 3.218 & 1.333 & 7.679 & 2.671 & 0.054 & 1.184 & 14.565 & 20.158 & 8.323 \\
\hline 2015 & 3.705 & 2.401 & 1.341 & 11.517 & 1.076 & 0.908 & 5.192 & 4.960 & 2.721 & 1.047 & 6.673 & 2.664 & 0.072 & 0.889 & 17.384 & 20.887 & 8.348 \\
\hline 2016 & 4.257 & 2.376 & 1.390 & 10.032 & 1.034 & 0.947 & 8.612 & 4.920 & 3.342 & 0.785 & 5.736 & 2.844 & 0.090 & 0.968 & 20.854 & 21.817 & 7.454 \\
\hline
\end{tabular}


results illustrate that bilateral trade cost elasticity varies across trading partners ${ }^{7}$, depending on how intensely the exporting destination trades with China. In addition, trade-cost elasticity heterogeneity in bilateral trade is significantly revealed by the measurement results, as we compare the weighted average trade-cost elasticity in China's agricultural products exported to different trading partners.

\section{The relationship between Trade- cost elasticity and import shares}

Figure 1 plots the trade-cost elasticity of China's agricultural products in $2016^{8}$ against the corresponding import shares of trading partners ${ }^{9}$. The negative correlation between the two indexes indicates that the effect of trade costs varies depending on how intensely two countries trade with each other. Specifically, the higher the import share of trading partners with respect to China's agricultural products, the lower the weighted average trade-cost elasticity. For example, the first observation on the right corresponds to the Philippines, which provide 1.1 percent of its total imports, and its trade-cost elasticity is quite low at 0.79 . The second observation from the left corner corresponds to Japan's import share of 0.2 percent, and its trade-cost elasticity is 4.25. The third observation from the left-hand side corresponds to Turkey's import share of 0.04 percent, and its trade-cost elasticity is quite high at 20.85. Figure 1 also shows the 'one size fits all' trade-cost elasticity from the traditional gravity model by the horizontal line with the value of 7 . The differential effect of trade costs for China's agricultural exports is the evidence that the common 'one size fits all' trade-cost sensitivity is not reasonable. It cannot respond to changes in the competitive trade environment.

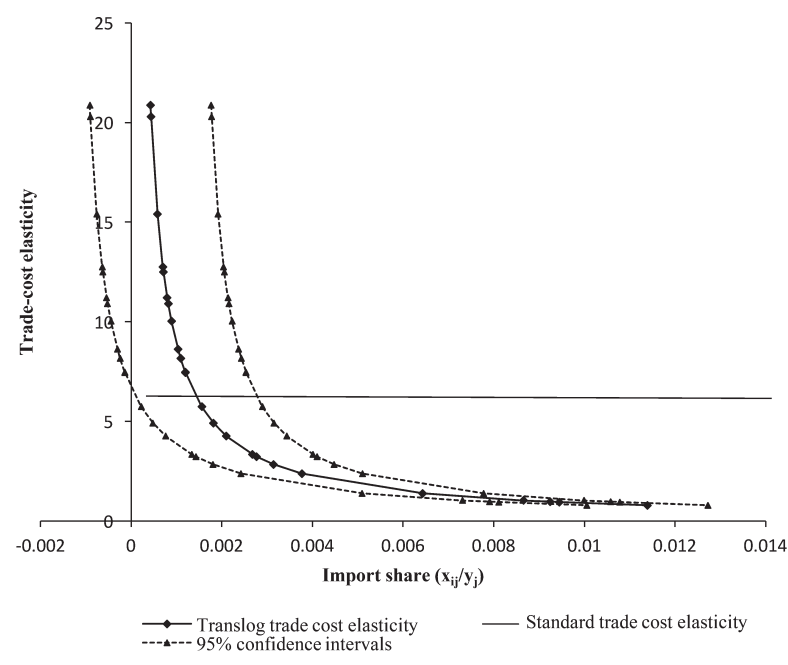

Fig. 1. Trade-cost elasticity of China's agricultural products in 2016.

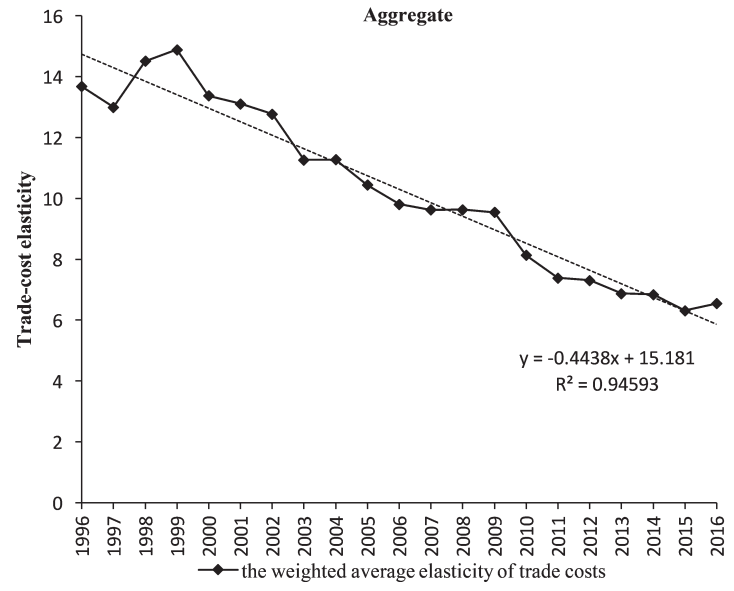

Fig. 2. Weighted average trade-cost elasticity as measured for China's agricultural products.

\section{Aggregate agriculture}

Figure 2 illustrates the weighted average elasticity of trade flows with respect to trade costs for China's aggregate agriculture trade with 33 trading partners over the sample period of 1996-2016. The measure is expressed as the trade-weighted average trade-cost elasticity, which is an average of its exporting trade-cost elasticity weighted by the value of trade with each trading partner. China's export of agricultural products experienced an obvious downward trend in trade-cost elasticity. More specifically, the trade-cost elasticity of China's agricultural products was 13.68 in 1996 and fell to 6.54 in 2016 , with a reduction of 52.13 percent. In addition, China's addition to the WTO facilitated its integration into the global economy. Before joining the WTO, the weighted average trade-cost elasticity of China's agricultural products strongly fluctuated. Since joining the WTO, the trend of China's agricultural export trade-cost elasticity to trading partners has been steadily dropping. Integration into the world economy has proven a powerful means for China to build closer economic relationships with trading partners. Trade liberalization and trade facilitation promote China's agricultural exports by breaking tariff and non-tariff trade barriers. However, the weighted average trade-cost elasticity was 6.57 in 2016, which is still high. This means that if trade costs fall by 1 percent, then trade is expected to go up by 6.57 percent. Reducing trade costs will continue to have a huge impact on China's agricultural exports.

\section{Different continents' countries}

Figure 3 illustrates the differential trade-cost elasticity across continental trading partners. The overall trend of the weighted average trade-cost elasticity in several intercontinental countries is heterogeneous. China's agricultural products face the highest trade-cost

\footnotetext{
8 The similar results hold for other years as well as the whole sample period.

${ }^{9}$ We plot Fig1 using the data within $95 \%$ confidence intervals of the import share $\left(\frac{x_{i j}}{y_{j}}\right)$.
} 
elasticity when entering North and South American markets, followed by European, Oceanic, African countries, and Asian countries, respectively. Specifically, the weighted average trade-cost elasticity for American countries was quite high at 19.8, followed by an elasticity of 12.8 for European countries and 10.9 for Oceanic countries in 2016. African countries' trade-cost elasticity was 6.9 , which was higher than the 2.2 for Asian countries in 2016. Taking into account that geographical distance is still the main factor affecting import shares, Asian countries were China's major trading partners for a long time. They were also important export markets for China's agricultural products. However, American countries are geographically far from China. Sino-US bilateral trade is more sensitive to trade costs. However, the trade-cost elasticity facing China's agricultural exports to American trading partners experienced a rapidly downward trend. It declined from 82.7 in 1996 to 19.8 in 2016, a reduction of 76 percent. The trade-cost elasticity for European, Oceanic, and African countries present a relatively modest trend. The weighted average tradecost elasticity with respect to Asian trading partners in the sample period only ranges from 2 to 5 . Figure 3 shows that China's agricultural exports to several intercontinental countries experience an obviously convergent trend in weighted average trade-cost elasticity from 2008. The gap between America and Asia narrows from 78.2 in 1996 to 17.6 in 2016. Specifically, the weighted average trade-cost elasticity in China's agricultural exports to American countries declined by a staggering 70.9 percent between 1996 and 2008, but Asian countries' trade-cost elasticity went down by 28.79 percent. After 2008, the trade-cost elasticity of American coun-

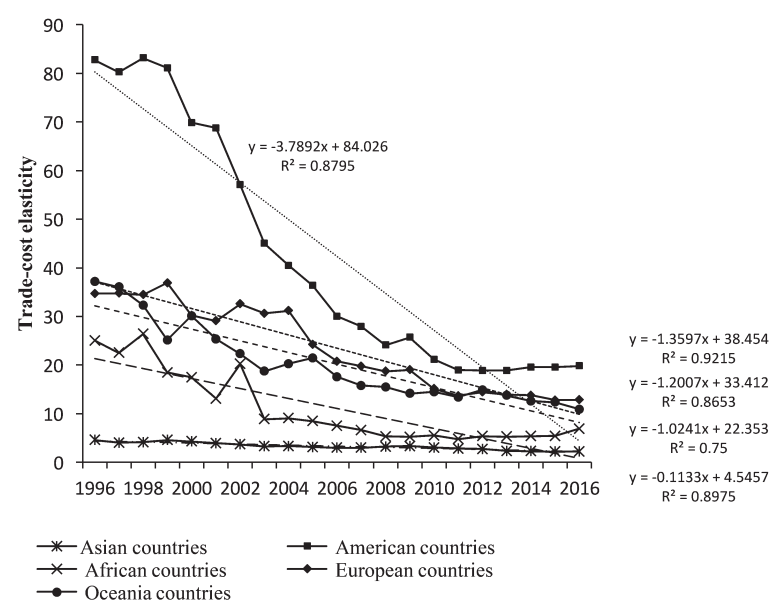

Fig. 3. Weighted average trade-cost elasticity of China's agricultural products across continents. tries experienced a relatively modest downward trend. The elasticity for American countries was 24.1 in 2008 and 19.8 in 2016, a reduction of 17.7 percent. For Asian countries, the value changes from 3.2 in 2008 to 2.2 in 2016, corresponding to a 30.4 percent decrease. Bilateral trade grows faster when the initial trade relationship was thin. When they already engaged in a lot of trade, country pairs hardly benefit. It also reveals that the overall decline in trade-cost elasticity is largely caused by the American trading partners.

\section{Developed countries vs Developing countries}

We categorize trading partners as developed ${ }^{10}$ or developing ${ }^{11}$ countries according to the International Monetary Fund's development classification. We compare the weighted average trade-cost elasticity of China's agricultural export patterns with developed and developing trading partners. Figure 4 shows that the tradecost elasticity of developed countries with respect to China's agricultural products is higher than that for developing countries. However, the gap narrows from 16.83 in 1996 to 8.18 in 2016. The trade-cost elasticity facing China's agricultural exports to developed trading partners experienced an obvious decline. Specifically, the trade-cost elasticity declined from 21.1 in 1996 to 10.9 in 2016, an average annual reduction rate of 2.3 percent. However, the trade-cost elasticity of developing countries experienced a less significant decline. The weighted average trade-cost elasticity with respect to developing partners in sample period only ranges from 2 to 5. It was only 4.25 in 1996 and dropped to 2.72 in 2016, an average annual reduction rate of 1.7 percent. There was a willingness by developed countries to maintain protectionist trade policies in their agricultural sectors. Therefore, the resistance of developed countries to import China's agricultural products is greater than that

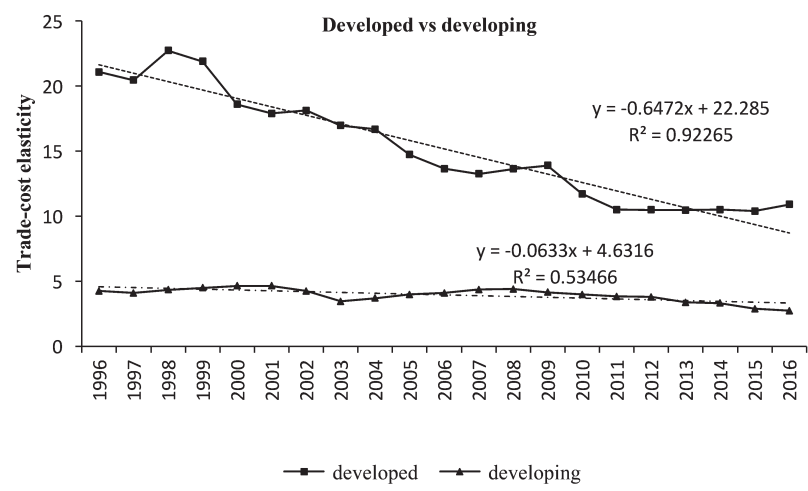

Fig. 4. Weighted average trade-cost elasticity of China's agricultural products across developmental partner groups.

${ }^{10}$ The 12 developed countries/regions include Australia(AUS), Belgium(BEL), Canada(CAN), Germany(DEU), Spain(ESP), France(FRA), United Kingdom(GBR), Japan(JPN), Italy(ITA), Republic of Korea(KOR), Netherlands(NLD), United States of America(USA).

${ }^{11}$ The 21 developing countries/regions include China, Hong Kong(HKG), Thailand(THA), Malaysia(MYS), Bangladesh(BGD), Philippines(PHL), Indonesia(IDN), Russian Federation(RUS), India(IND), Singapore(SGP), Pakistan(PAK), Brazil(BRA), Benin(BEN), Nigeria(NGA), Myanmar(MMR), Togo(TGO), Sri Lanka(LKA), Egypt(EGY), Iran(IRN), South Africa(ZAF), Turkey(TUR), Mexico(MEX). 
of developing countries. The import value of developed countries with respect to China's agricultural products is lower. Additionally, the income level of developed countries is higher than that of developing countries. The import share of developed countries is smaller than that of developing countries. Developed countries are more sensitive to trade costs.

\section{RTA countries vs non-RTA countries}

Trade-cost elasticity heterogeneity in bilateral trade is clearly revealed in Figure 5. In Figure 5 we compare the weighted average trade-cost elasticity of China's agricultural exports to $\mathrm{RTA}^{12}$ countries with those of non-RTA ${ }^{13}$ countries from 1996 to 2016 . The trade-cost elasticity of non-RTA countries in the sample period ranges from 14 to 52 , which is significantly higher than those for RTA countries (2 to 5). However, the gap narrows from 45.18 in 1996 to 12.59 in 2016 . Specifically, the trade-cost elasticity of China's agricultural exports fell very rapidly, as is evidenced by a reduction of approximately 69.9 percent when entering non-RTA markets. However, the trade-cost elasticity facing China's agricultural exports to RTA trading partner experienced a relatively gentle decline, with an average annual reduction rate of 2.3 percent. This means that it was necessary to reduce trade costs with respect to non-RTA countries. However, individual RTA trading partners still have trading potential. For example, the trade-cost elasticity for India was 20.29 in 2016. It was higher than other nonRTA trading partners' trade-cost elasticity, such as with an elasticity of 5.7 for Russia. In recent years, China engaged in multilateral or bilateral negotiations to sign free trade agreements (FTAs). As of 2016, China had 14 FTAs in operation, with another 8 under negotiation and another 6 under preliminary consultation. FTAs will eliminate certain tariffs and non-tariffs barriers and facilitate economic and trade cooperation.

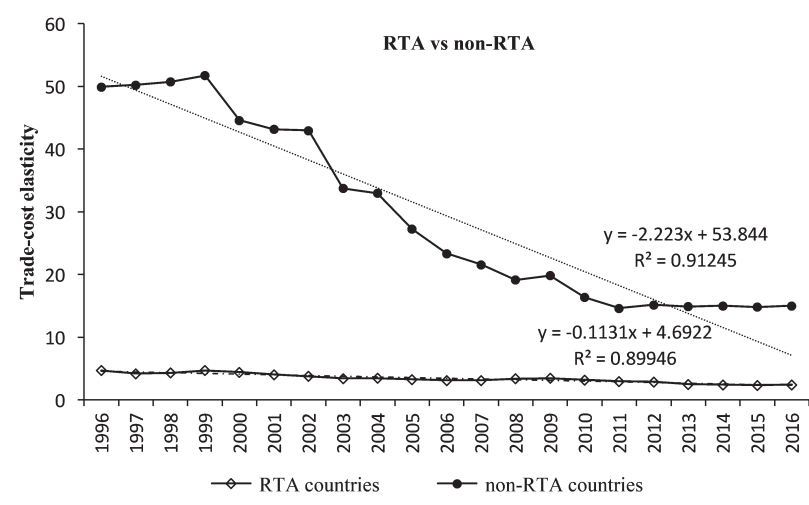

Fig. 5. Weighted average trade-cost elasticity of China's agricultural products across RTA partner groups

\section{CONCLUSIONS}

This paper applies a trade-cost elasticity equation based on the translog gravity model developed by Novy (2013) to measure the trade-cost elasticity of China's agricultural exports. It applies a panel dataset for its major trading partners. In contrast to the traditional gravity equation based on CES, the translog gravity generates a variable, endogenous trade-cost elasticity. With respect to the realistic competitive trade environment, the flexible trade-cost elasticity is more reasonable and representative. Moreover, this method is parsimonious in its data requirements and easy to empirically implement.

The empirical results presented in this paper confirmed that trade-cost elasticity varies based on the intensely of the trade between two countries. We found there is a negative correlation between the import share of trading partners and trade-cost elasticity. Bilateral trade is more sensitive to trade costs when China provides a relatively smaller import share of agricultural products to its trading partners. Moreover, China's trade cost elasticity experienced an obviously downward trend during the period of 1996-2016. China has pursued export-oriented economic policies in recent years. The rapid increase of exports was followed by a reduction in trade-cost elasticity. However, the trade-weighted average trade-cost elasticity was 6.54 in 2016, which suggests that China still has agricultural exporting potential. The significant heterogeneity and substantial differences have been revealed in the measurement results, as we compare the weighted average trade-cost elasticity in China's agricultural products exported to different trading partners. On average, the trade-cost elasticity for American countries is the highest among several continents, and China's agricultural exports face a lower tradecost elasticity when entering other Asian markets. The trade-cost elasticity of developed trading partners with respect to China's agricultural products is higher than that for developing trading partners. Moreover, China's agricultural products face a higher trade-cost elasticity when exporting to the non-RTA countries than RTA countries.

This paper offers direct information on the estimate of China's agricultural trade-cost elasticity. It provides an accurate and convenient measure for trade cost elasticity, which is useful in the prediction of the effects of trade policy on trade flows. Furthermore, a variable trade-cost elasticity is more reasonable in order to quantify welfare gains from trade. Therefore, the trade-cost elasticity measured by this method can answer the question of how much trade costs reductions would promote China's agricultural exports.

${ }^{12}$ The 14 RTA countries/regions include Australia(AUS), Bangladesh(BGD), China, Hong Kong(HKG), India(IND), Indonesia(IDN), Japan(JPN), Republic of Korea(KOR), Sri Lanka(LKA), Myanmar(MMR), Malaysia(MYS), Pakistan(PAK), Philippines(PHL), Singapore(SGP), Thailand(THA).

${ }^{13}$ The 19 non-RTA countries/regions include Germany(DEU), Netherlands(NLD), Italy(ITA), United Kingdom(GBR), Canada(CAN), Spain(ESP), Mexico(MEX), Brazil(BRA), Benin(BEN), Nigeria(NGA), France(FRA), Togo(TGO), Belgium(BEL), Turkey(TUR), Egypt(EGY),Iran(IRN), South Africa(ZAF), Russian Federation(RUS), United States of America(USA). 


\section{AUTHOR CONTRIBUTIONS}

Conceived and designed the methodology: Xuejun WANG, Koshi MAEDA and Dan MENG. Analyzed the data: Dan MENG and Xuejun WANG. Wrote the paper: Dan MENG, Xuejun WANG and Koshi MAEDA.

\section{ACKNOWLEDGEMENTS}

The authors are grateful for funding support from the National Natural Science Foundation of China (71403128), Jiangsu Overseas Visiting Scholar Program for University Prominent Young \& Middle-aged Teachers and Presidents, and A Project Funded by the Priority Academic Program Development of Jiangsu Higher Education Institutions, China (PAPD).

\section{REFERENCES}

Anderson, J. E. and E. V. Wincoop 2003 Gravity with Gravitas: A Solution to the Border Puzzle. American Economic Review, 93: $170-192$
Caliendo, L. and F. Parro 2012 Estimates of the Trade and Welfare Effects of NAFTA. NBER Working Papers, 82: 1-44

Eaton, J. and S. Kortum 2002 Technology, Geography, and Trade. Econometrica, 70: 1741-1779

Fang, H., B. Peng, Z. Feng, and J. J. Wu 2010 Research on Measurement of Bilateral Costs of International Trade-Based on Revised Gravity Model. Finance \& Trade Economics, 5: 71-76 Hummels, D. and P. J. Klenow 2005 The Variety and Quality of a Nation's Exports. American Economic Review, 95: 704-723

Novy, D. 2013 International trade without CES: Estimating translog gravity. Joumal of International Economics, 89: 271-282

Romalis, J. 2007 NAFTA's and CUSFTA's Impact on International Trade. Review of Economics \& Statistics, 89: 416-435

Shi, B. Z. 2008 The Measurement of Trade Cost between China and Its Main Trade Partners-Based on the Revised Gravity Model. Journal of International Trade, 11: 24-30

Simonovska, I. and M. E. Waugh 2012 Different Trade Models, Different Trade Elasticities. Mimeo UC Davis

Wang, X. J., G. Z. Han, K. Maeda and Y. H. Zhou 2016 China's Agricultural Trade Costs: Measurement and Determinants. Journal of Faculty of Agriculture Kyushu University, 61 215-223

$\mathrm{Xu}, \mathrm{D}$. Y. and Q. Liang 2010 The measurement and analysis of China's foreign bilateral trade costs: 1981-2007. The Journal of Quantitative and Technical Economics, 1: 119-127 